\title{
Why I believe nanoparticles are crucial as a carrier for targeted drug delivery
}

James R. Baker, Jr*

Nanoparticles are the only materials small enough to target cells in the body, and therefore are crucial to targeted drug delivery. Issues with the synthesis, consistency, and bioactivity of these molecules are still being addressed, but base on current proof of concept studies there is a reason to believe that the 'holy grail' of targeted drug delivery might someday be achieved using nanoparticle-based systems. ๑ 2013 Wiley Periodicals, Inc.

How to cite this article:

WIREs Nanomed Nanobiotechnol 2013, 5:423-429. doi: 10.1002/wnan.1226

\section{THE CONCEPT OF TARGETED DRUG DELIVERY}

$\mathrm{T}$ argeted drug delivery has been one of the most elusive goals of medical therapy. ${ }^{1}$ Unlike conventional molecular targeting, where there is a unique biological activity that is the focus of the therapeutic, targeted drug delivery involves the concept that a drug can be delivered to a specific cell or cell type. ${ }^{2}$ In this case, a therapeutic can have a desired effect but targeting minimizes the side effects often associated with entry into nontargeted normal cells. Targeting can provide remarkable improvements in the therapeutic index of an agent (Figure 1), which can allow drugs with excess toxicity to be used safely and effectively. ${ }^{3}$ In addition, it can improve the desired effect of an agent by delivering higher concentrations of a molecule to the targeted cell, potentially overcoming resistance to a therapeutic. ${ }^{4}$ While targeted drug delivery has been predominantly associated with cancer chemotherapy, where the side effects of cytotoxic drugs are devastating, it also offers opportunities for the treatment of cardiovascular, metabolic, and inflammatory diseases where higher doses of potentially useful therapies are required than can be safely used in human applications. ${ }^{5}$ However,

*Correspondence to: jbakerjr@umich.edu

Michigan Nanotechnology Institute, University of Michigan, Ann Arbor, MI, USA

Conflict of interest: The author has declared no conflicts of interest for this article. numerous technical limitations have prevented the development of most applications of targeted drug delivery. ${ }^{6}$ To understand these limitations, it is important to examine the functional requirements for the targeted therapeutics; this will also provide insights as to why nanomaterials might be useful in these applications.

\section{REQUIREMENTS FOR TARGETED DRUG DELIVERY}

Conventional therapeutics are typically small molecule drugs $(\mathrm{MW}<1000 \mathrm{Da})$. Once injected or absorbed from the gastrointestinal tract these molecules can easily diffuse through vascular pores, escaping the bloodstream, and dispersing through the tissue matrix to reach cells. ${ }^{7}$ These molecules can then pass across the cell membrane into the interior and the nucleus of the cell where they have their action. In contrast, targeted therapeutics utilize a delivery system based on carrier macromolecules that are orders of magnitude larger in size (Figure 2). Most targeted therapeutics have two molecules coupled to a carrier; one chemical entity responsible for targeting and another being the therapeutic. ${ }^{8}$ In addition, a companion diagnostic imaging agent to identify the presence of the target uses the same targeting platform with an imaging molecule, again requiring two molecules. In both cases, these small molecules are linked to the macromolecular backbone that often is too large to escape the vasculature or traverse 


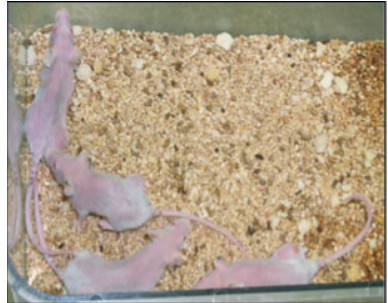

Free drug

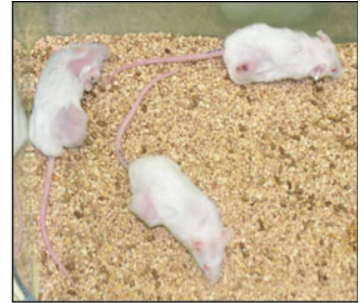

Targeted drug
FIG URE 1 | The ability of targeted drug therapy to reduce drug toxicity. Mice on left dosed with free methotrexate lose weight, hair and appear sick due to systemic toxicity. Mice on right dosed with folate-targeted dendrimer methotrexate exhibit no adverse effects from the chemotherapy but have drug-induced necrosis of the tumor on the mice.

the tissue space. While there is some debate about whether molecules like liposomes can escape the vasculature $^{9}$ a real key is the nature of the vasculature targeted. Tumor vasculature in animals is 'leaky' and this has allowed larger molecules to escape and be retained in tumors. This has allowed for tumor therapy based on 'enhanced permeability and retention' (EPR) where carrier bound drug accumulates in tumors. In contrast, drug carriers that can escape normal vascular pores are probably about the same size as the largest of proteins $(<20 \mathrm{~nm}) .{ }^{10}$ Studies have documented that molecules $>100 \mathrm{~nm}$ in diameter do not effectively diffuse across normal endothelium, ${ }^{11}$ and in some cases even molecules $40 \mathrm{~nm}$ in diameter are problematic unless the endothelium is traumatized by radiation or heating. ${ }^{12}$ Thus, targeted therapeutics for nontumor applications must still be small enough to exit the vasculature and/or traverse the interstitial space in order to reach a target cell. Once at a target cell, therapeutic particles have traditionally needed to enter a cell. If the entire targeted therapeutic carrier is required to enter the cell, size again becomes a problem as studies with genetic therapeutics have shown that anything greater than $150 \mathrm{~nm}$ does not effectively enter cells. ${ }^{13}$ While this can be facilitated if there is release of the drug from the carrier (see Conclusions), this can be technically challenging. Thus, targeted drug delivery, particularly for noncancer applications, has awaited the development of smaller carrier structures to serve as the basis for complex therapeutics.

\section{NEW OPPORTUNITIES AFFORDED BY THE EMERGING FIELD OF NANOSCIENCE}

Nanotechnology has led to a remarkable convergence of disparate fields to address drug delivery, including biology, applied physics, optics, computational analysis, and modeling, as well as materials science. Because of this, the application of nanoscale analytical, computational, and synthetic approaches to understanding and manipulating complex systems involved in drug delivery offers incredible potential for advances in the diagnosis and treatment of human diseases. However, despite the growing interest in nanotechnology-based therapeutics, there are still many questions as to why nanotechnology is crucial to therapeutic development. Most investigators focus on the unique aspects of the technology when discussing nanotechnology for drug delivery. However, my perspective is that the utility of nanotechnology in targeted therapeutic development lies in requirements based on the structure of biological systems. In this regard, the need for carrier materials to be less nanometers in diameter for targeted drug delivery in the absence of EPR is defined by biology, not by technology. Therefore, the ability to design and synthesize materials in the nanoscale size range is the key facilitating element that allows for the development of targeted therapeutics.

Described another way, a 'nanotherapeutic' is a complex, multicomponent material that can be designed and synthesized specifically to target drug,
FIGURE 2 | The challenges of drug delivery in reaching targeted cells.

\section{Targeted therapeutics must:}

1) Diffuse out of blood vessels (particle size $<20 \mathrm{~nm}$ )

2) Clear the body safely and rapidly

3) Recognize target cells and bind with high avidity and specificity

4) Internalize into target cells to deliver the therapeutic

5) Maintain drug stability and solubility in bodily fluids

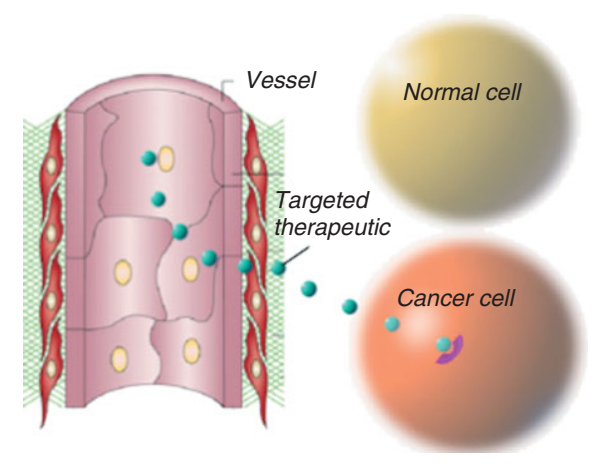




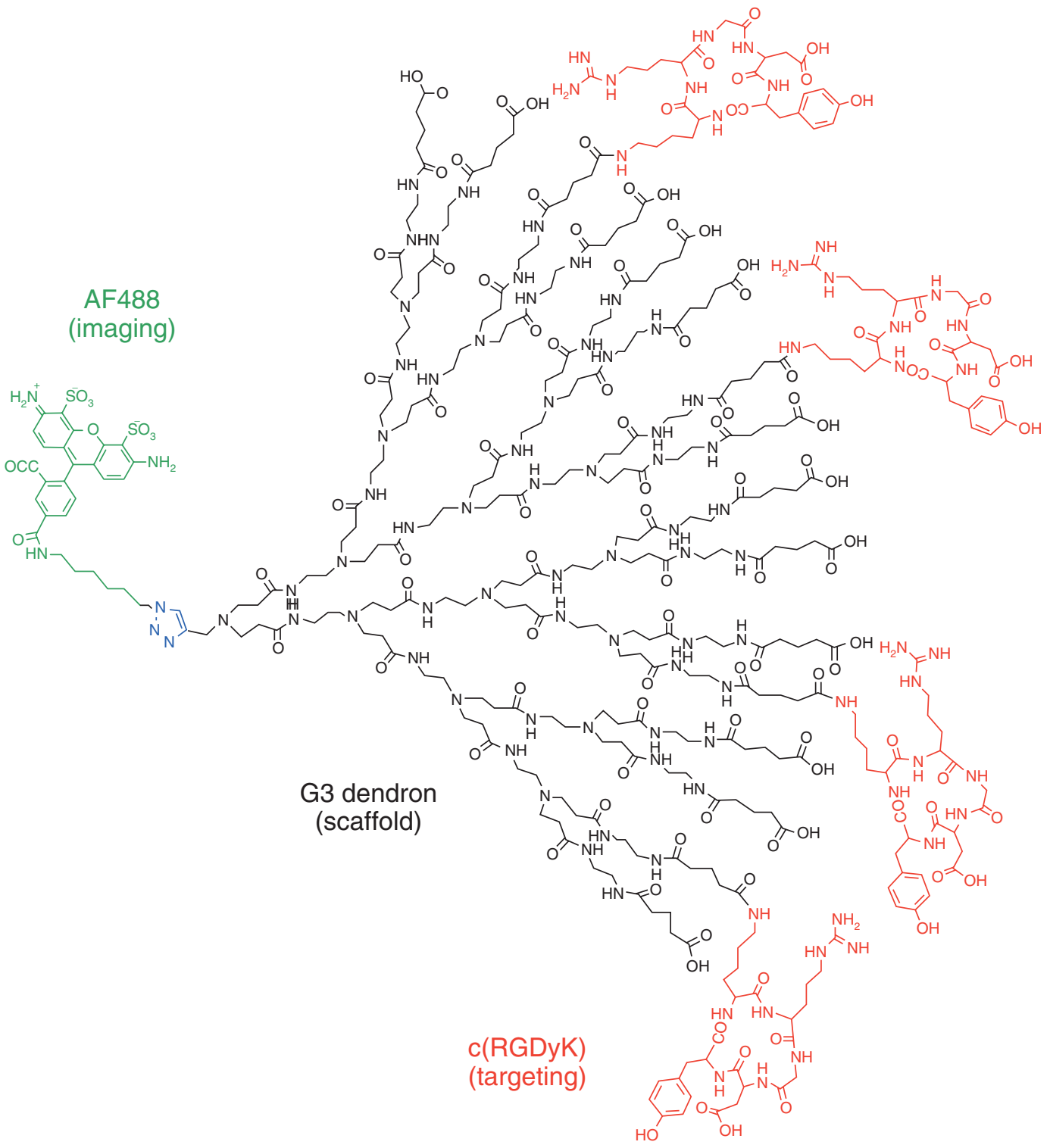

FIG URE 3 | A dendron where a single dye molecule is coupled to multiple targeting ligands. This can also be used to target drugs as well as dyes, and allows for every carrier to have one drug and multiple ligands for high avidity interactions and efficient targeting.

but remains small enough to pass through the tissue matrix from the vasculature to target cells. ${ }^{14}$ Once at a tissue target, the therapeutic must be able to identify and bind specifically to the targeted cell. This may involve identifying the specific expression or unique alterations of molecules on cell membranes, but these changes must be able to differentiate the targeted from normal cells. In addition, these molecules must then enter the cell and have a biological effect. This means carrying a drug or genetic therapeutic into a cell, but requires that the therapeutic either be active as part of the targeted delivery system or is released from the carrier within the cell. This latter approach provides another level of complexity to the function of a targeted therapeutic. Therefore, it is obvious that a nanotherapeutic is inherently a complex but remarkably small molecule that serves several functions to yield the targeted delivery of a therapeutic.

Utilizing these advances, our interdisciplinary team at the University of Michigan Nanotechnology Institute for Medicine and Biological Sciences (M-NIMBS) has developed a technical solution that provides a scaffold and linking strategy that allows the synthesis of multifunctional combinatory therapeutics can be designed and built. ${ }^{15}$ The scaffold is a dendritic polymer that is uniquely suited to 
biomedical applications and has a diameter of only $5 \mathrm{~nm} .{ }^{16,17}$ We use multiple linker mechanisms to couple therapeutics to the carrier molecules, including click chemistry and oligonucleotide bridges (Figure 3). We have completed extensive studies providing proof of concept ${ }^{18,19}$ and have taken development of several nanodevices through small animal trials. These designed multifunctional devices will have applications as targeted imaging and diagnostic agents for several diseases at all stages of illness.

\section{MULTIFUNCTIONAL SINGLE DENDRIMER NANODEVICES IN VITRO TESTING}

Over the past several years, we have made great progress in developing dendrimer-based, multifunctional therapeutics. We have produced a single dendritic molecule that has folate for targeting, methotrexate for sensing, and gadolinium or dye molecules for imaging (Figure 4). This involves coupling of these functional groups to the surface of a generation 5 PAMAM dendrimer (MW 25,000 Da, diameter $5 \mathrm{~nm}$ ). Doing these conjugates has proven to be an arduous synthetic endeavor given the multiple chemical steps that are required. Several challenging protect-deprotect steps are needed to produce such a multifunctional agent. This dendrimer-based agent was used as a testing platform to evaluate the therapeutic capability of this type of molecule. The studies involved with developing these molecules have been previously and extensively described. ${ }^{20-24}$ While this was not an entirely optimized system, the size $(5-6 \mathrm{nM})$, molecular weight $(40 \mathrm{kDa})$ and solubility of this macromolecular system have provided a material that can be used to evaluate structural aspects of the polymer scaffold, cell delivery, and internalization to test concepts of nanoparticle delivery.

\section{TARGETING CANCER}

We first demonstrated the ability to use dendrimers to target drugs to specific cells in a cancer model. ${ }^{25}$ This model involves subcutaneous tumors that express the folate receptor on $\mathrm{KB}$ squamous carcinoma cells. These cells are implanted subcutaneously in a nude mouse and then drug is administered to see the effect on the growth of the cancer cells. This model does not exactly represent the physiology of human tumors, but can be employed to measure the relative pharmacokinetics of targeted and free drug. We injected folate-targeted dendrimers that also had methotrexate and fluorescein on their surface

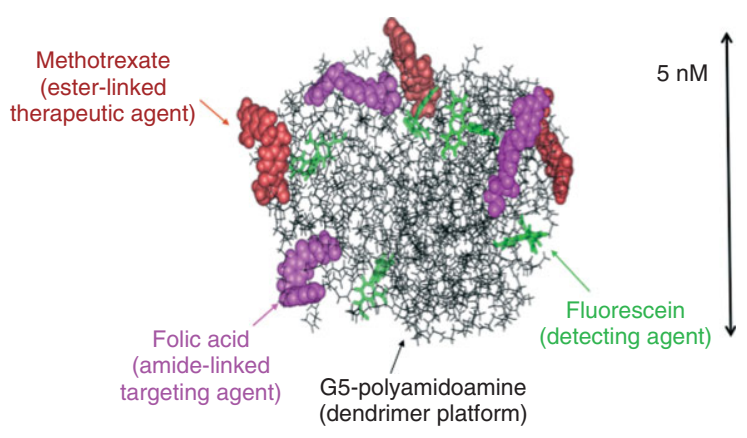

FIGURE 4 | A multifunctional dendrimer containing a targeting molecule (folate), a drug (methotrexate), and a dye molecule (fluorescein), the latter used to follow the therapeutics in vivo distribution.
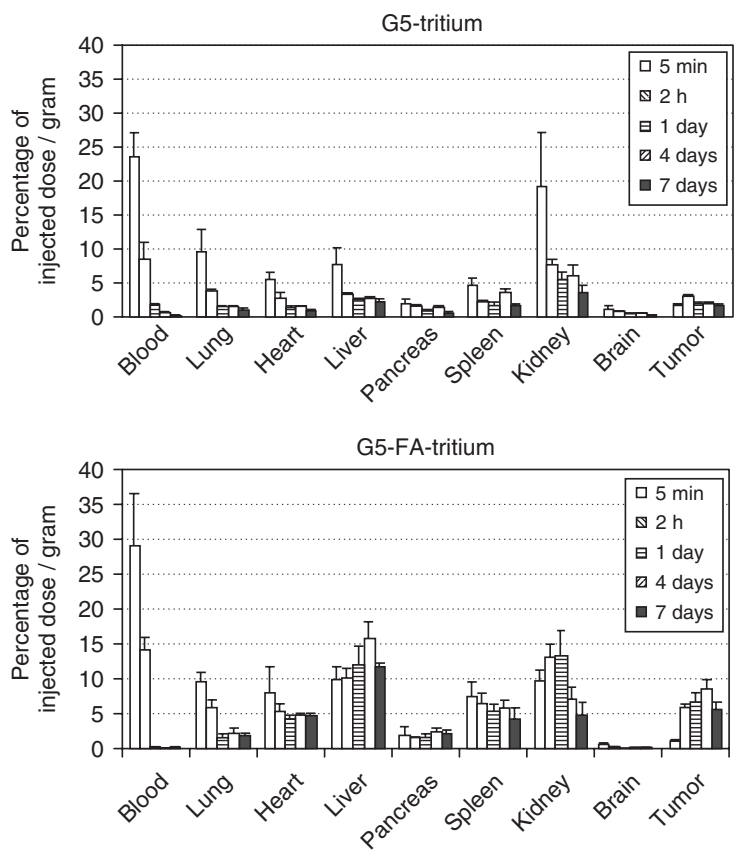

FIGURE 5 | The biodistribution of targeted versus nontargeted tritium-labeled dendrimers. Note that the uptake in the folate receptor positive tumor was 10 -fold higher in the targeted dendrimers and persisted over time.

through the tail vein in tumor bearing mice and were able to demonstrate specific uptake in the tumor through fluorescence studies using labeled dendrimer. In addition, there was decreased toxicity compared to free drug and an improved therapeutic effect. The material was not internalized into other organs with cells that have the reduced folate carrier because at 5 $\mathrm{nM}$ diameter dendrimer was too large to go through that ion channel. Despite this size, the dendrimer therapeutic was still below the filtration threshold of the kidney and was able to be excreted in the urine. As a result, the therapy was not toxic and readily 
Triazine scaffold

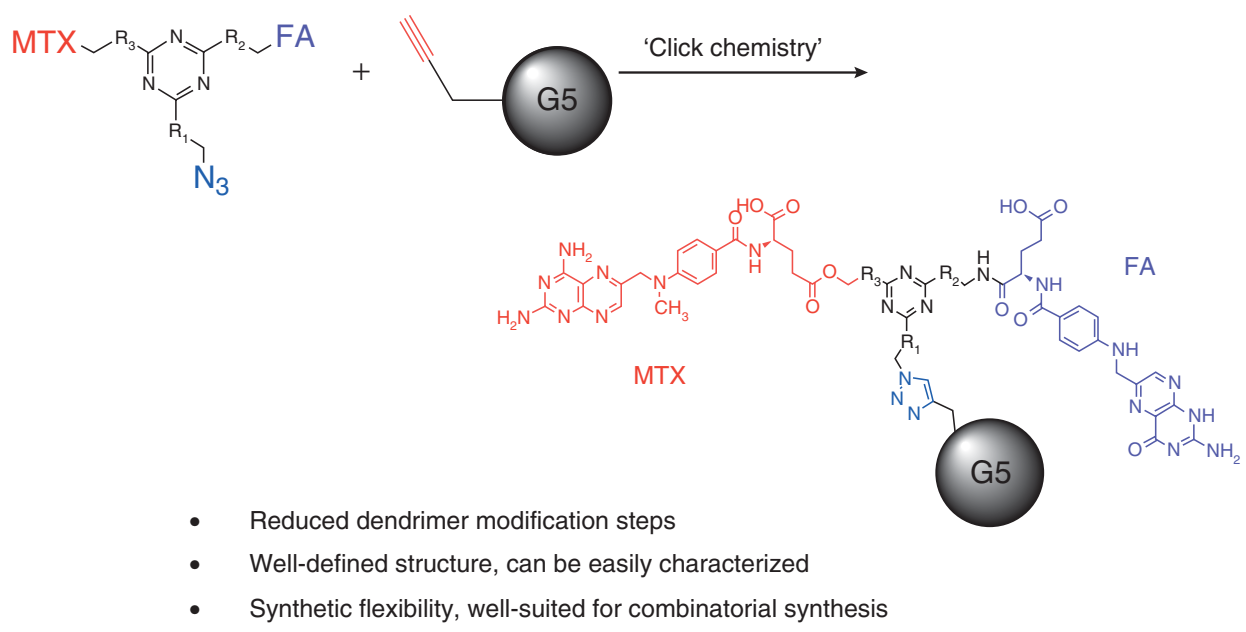

FIG URE 6 | Coupling both drug (methotrexate) and targeting ligand (folate) to a dendrimer using a triazine linker and click chemistry offers more efficient coupling and fixed ratios of drug and targeting ligand.

left the body if it was in internalized into the tumor. There was a 10 -fold improvement in tumor targeting with almost $10 \%$ of the injected drug ending up in the tumor (Figure 5). This suggested that systemically administered nanoparticles could target tumors and could improve the therapeutic index of drugs.

\section{TARGETING ARTHRITIS}

Recently, we have examined targeting folate receptor expressing cells (activated macrophages) responsible for inflammation in arthritis using the same folate targeted nanoparticles. ${ }^{26}$ These studies documented that the targeted nanoparticles were taken up by activated macrophages bearing folate receptors and suppressed inflammatory activities of these cells more potently than free drug. There was also less toxicity as documented by the fact that the splenic weights of targeted drug treated animals were not decreased. This suggested that as compared to free drug targeted drug effects were limited to cells in inflamed tissue expressing folate receptors were targeted. This approach may provide better responses to methotrexate in arthritis and overcome doselimiting toxicity of this drug.

\section{REMAINING ISSUES WITH NANOPARTICLE THERAPY}

While it is clear from the above studies that nanoparticle-targeted drugs could be very useful as therapeutics there are potential concerns and there are a number of issues that need to be resolved before these molecules enter clinical trials. There is a problem with the distribution of targeting ligands and drug molecules on the nanoparticles. Current coupling techniques give a broad distribution of molecules on the nanoparticles within synthesized populations. ${ }^{27}$ The result of this is a population of drug delivery molecules that have a range of targeting ligands and drugs, and only a small portion of the molecules $(\sim 10 \%)$ actually have the desired effect. We are currently examining click chemistry approaches and new approaches at dendrimer synthesis to improve the uniformity of these therapeutic populations. ${ }^{28}$ Another approach is to use coupling chemistries with set ratios of drug and targeting molecule ${ }^{29}$ (Figure 6). While there would still be a distribution of molecules in the overall population, the ratios of drug to targeting ligand would be fixed. This should improve the uniformity and function of the therapeutics. Another improvement may come from more uniform dendrimers and other types of nanoparticles that reduce the poly-dispersity of the backbone and provide a more uniform platform to attach molecules. ${ }^{30}$

Exciting work from several groups also looks to resolve some of the issues with the biological limitations imposed on nanoparticle therapies. The need for the therapeutic to transverse biological barriers, such as vascular endothelium and blood brain barrier, has recently been addressed. ${ }^{31}$ This type of approach, where facilitated transport overcomes size limitations imposed by simple membrane diffusion, could yield exciting new types of therapies for some of the most difficult to react targets such as nonvascularized tumors or the brain. Also, new approaches to drug 
release and uptake by targeted cells may allow delivery of drugs without requiring internalization of the nanoparticle carrier. ${ }^{32,33}$ These types of advances will allow for the more facile design of nanoparticle therapeutics and even higher levels of delivered drug. This again should increase the therapeutic index for drugs involved in these delivery systems.

\section{CONCLUSIONS}

Nanoparticles are uniquely suited to target drugs to cells because of the inherent size limitations placed by biological systems. In addition, the ability to couple multiple molecules to a single nanoparticle in a consistent and effective manner is a necessary requirement to create the ability to make complex therapeutics that are consistently capable of targeting cells. While there are still significant design and engineering concerns, the ability to make complex therapeutics that have diagnostic and imaging agents coupled on the same molecule to allow monitoring of drug therapy truly provide a unique opportunity for improving therapeutics.

\section{REFERENCES}

1. Zamboni WC, Torchilin V, Patri AK, Hrkach J, Stern S, Lee R, Nel A, Panaro NJ, Grodzinski P. Best practices in cancer nanotechnology: perspective from NCI nanotechnology alliance. Clin Cancer Res 2012, 18:3229-3241.

2. Woyach JA, Johnson AJ, Byrd JC. The B-cell receptor signaling pathway as a therapeutic target in CLL. Blood 2012, 120:1175-1184.

3. Li C, Wallace S. Polymer-drug conjugates: recent development in clinical oncology. Adv Drug Deliv Rev 2008, 60:886-898.

4. Raguz S, Yagüe E. Resistance to chemotherapy: new treatments and novel insights into an old problem. $\mathrm{Br} J$ Cancer 2008, 99:387-391.

5. Colson YL, Grinstaff MW. Biologically responsive polymeric nanoparticles for drug delivery. Adv Mater 2012, 24:3878-3886.

6. Cheng Z, Al Zaki A, Hui JZ, Muzykantov VR, Tsourkas A. Multifunctional nanoparticles: cost versus benefit of adding targeting and imaging capabilities. Science 2012, 338:903-910.

7. Penner N, Xu L, Prakash C. Radiolabeled absorption, distribution, metabolism, and excretion studies in drug development: why, when, and how? Chem Res Toxicol 2012, 25:513-531.

8. Majoros IJ, Myc A, Thomas T, Mehta CB, Baker JR Jr. PAMAM dendrimer-based multifunctional conjugate for cancer therapy: synthesis, characterization, and functionality. Biomacromolecules 2006, 7:572-579.

9. Sreeramoju P, Libutti SK. Strategies for targeting tumors and tumor vasculature for cancer therapy. Adv Genet 2010, 69:135-152.

10. Heneweer C, Gendy SE, Peate-Medina O. Liposomes and inorganic nanoparticles for drug delivery and cancer imaging. Ther Deliv 2012, 3:645-656.

11. Rippe B, Davies S. Permeability of peritoneal and glomerular capillaries: what are the differences according to pore theory? Perit Dial Int 2011, 31:249-258.

12. Sun X, Xing L, Ling CC, Li GC. The effect of mild temperature hyperthermia on tumour hypoxia and blood perfusion: relevance for radiotherapy, vascular targeting and imaging. Int J Hyperthermia 2010, 26:224-231.

13. Ulasov AV, Khramtsov YV, Trusov GA, Rosenkranz AA, Sverdlov ED, Sobolev AS. Properties of PEIbased polyplex nanoparticles that correlate with their transfection efficacy. Mol Ther 2011, 19:103-112.

14. Arosio D, Casagrande C, Manzoni L. Integrin-mediated drug delivery in cancer and cardiovascular diseases with peptide-functionalized nanoparticles. Curr Med Chem 2012, 19:3128-3151.

15. Rawat A, Vaidya B, Khatri K, Goyal AK, Gupta PN, Mahor S, Paliwal R, Rai S, Vyas SP. Targeted intracellular delivery of therapeutics: an overview. Pharmazie 2007, 62:643-658.

16. Quintana A, Raczka E, Piehler L, Lee I, Myc A, Majoros I, Patri AK, Thomas T, Mule J, Baker JR Jr. Design and function of a dendrimer-based therapeutic nanodevice targeted to tumor cells through the folate receptor. Pharm Res 2002, 19:1310-1316.

17. McNerny DQ, Leroueil PR, Baker JR. Understanding specific and nonspecific toxicities: a requirement for the development of dendrimer-based pharmaceuticals. Wiley Interdiscip Rev Nanomed Nanobiotechnol 2010, 2:249-59.

18. McNerny DQ, Kukowska-Latallo JF, Mullen DG, Wallace JM, Desai AM, Shukla R, Huang B, Banaszak Holl MM, Baker JR Jr. RGD dendron bodies; synthetic avidity agents with defined and potentially interchangeable effector sites that can substitute for antibodies. Bioconjug Chem 2009, 20:1853-1859.

19. Choi Y, Thomas T, Kotlyar A, Islam MT, Baker JR Jr. Synthesis and functional evaluation of DNA-assembled polyamidoamine dendrimer clusters for cancer cellspecific targeting. Chem Biol 2005, 12:35-43. 
20. Majoros IJ, Williams CR, Becker A, Baker JR Jr. Methotrexate delivery via folate targeted dendrimer-based nanotherapeutic platform. Wiley Interdiscip Rev Nanomed Nanobiotechnol 2009, 1: 502-510.

21. Myc A, Kukowska-Latallo J, Cao P, Swanson B, Battista J, Dunham T, Baker JR Jr. Targeting the efficacy of a dendrimer-based nanotherapeutic in heterogeneous xenograft tumors in vivo. Anticancer Drugs 2010, 21:186-192.

22. Shukla R, Thomas TP, Desai AM, Kotlyar A, Park SJ, Baker JR. HER2 specific delivery of methotrexate by dendrimer conjugated anti-HER2 mAb. Nanotechnology 2008, 19:295102.

23. Shukla R, Thomas TP, Peters J, Kotlyar A, Myc A, Baker JR Jr. Tumor angiogenic vasculature targeting with PAMAM dendrimer-RGD conjugates. Chem Commun (Camb) 2005, 46:5739-5741.

24. Majoros IJ, Thomas TP, Mehta CB, Baker JR Jr. Poly(amidoamine) dendrimer-based multifunctional engineered nanodevice for cancer therapy. J Med Chem 2005, 48:5892-5899.

25. Kukowska-Latallo JF, Candido KA, Cao Z, Nigavekar SS, Majoros IJ, Thomas TP, Balogh LP, Khan MK, Baker JR Jr. Nanoparticle targeting of anticancer drug improves therapeutic response in animal model of human epithelial cancer. Cancer Res 2005, 65:5317-5324.

26. Thomas TP, Goonewardena SN, Majoros IJ, Kotlyar A, Cao Z, Leroueil PR, Baker JR Jr. Folatetargeted nanoparticles show efficacy in the treatment of inflammatory arthritis. Arthritis Rheum 2011, 63:2671-2680.
27. Mullen DG, Fang M, Desai A, Baker JR, Orr BG, Banaszak Holl MM. A quantitative assessment of nanoparticle-ligand distributions: implications for targeted drug and imaging delivery in dendrimer conjugates. ACS Nano 2010, 4:657-670.

28. Huang B, Desai A, Zong H, Tang S, Leroueil P, Baker JR Jr. Copper-free click conjugation of methotrexate to a PAMAM dendrimer platform. Tetrahedron Lett 2011, 52:1411-1414.

29. Zong H, Thomas TP, Lee KH, Desai AM, Li MH, Kotlyar A, Zhang Y, Leroueil PR, Gam JJ, Banaszak Holl MM, et al. Bifunctional PAMAM dendrimer conjugates of folic acid and methotrexate with defined ratio. Biomacromolecules 2012, 13:982-991.

30. Huang B, Kukowska-Latallo JF, Tang S, Zong H, Johnson KB, Desai A, Gordon CL, Leroueil PR, Baker JR Jr. The facile synthesis of multifunctional PAMAM dendrimer conjugates through copper-free click chemistry. Bioorg Med Chem Lett 2012, 22:3152-3156.

31. Chrastina A, Massey KA, Schnitzer JE. Overcoming in vivo barriers to targeted nanodelivery. Wiley Interdiscip Rev Nanomed Nanobiotechnol 2011, 3:421-437.

32. Pan D, Sanyal N, Schmieder AH, Senpan A, Kim B, Yang X, Hu G, Allen JS, Gross RW, Wickline $\mathrm{SA}$, et al. Antiangiogenic nanotherapy with lipaselabile Sn-2 fumagillin prodrug. Nanomedicine 2012, 10:1507-1519.

33. Zhou HF, Yan H, Senpan A, Wickline SA, Pan D, Lanza GM, Pham CT. Suppression of inflammation in a mouse model of rheumatoid arthritis using targeted lipaselabile fumagillin prodrug nanoparticles. Biomaterials 2012, 33:8632-8640. 